\title{
Magnetic Resonance Imaging as an Effective Tool for Successful Localization of Superior Mediastinal Parathyroid Adenoma
}

\author{
Tatsuya ShImAdA, Kiichiro HIgASHI, Keishi KIMURA, Tadahiro SHIDO, \\ Kazuo NAMIKAWA*, Jun-ichi MiZUTANI*, Miyuki DOIGUCHI* \\ and Kazunori MIURA**
}

\begin{abstract}
Noninvasive diagnostic procedures for the preoperative localization of parathyroid tumors were performed on a 59-year-old woman with hypercalcemia. In this case, sonography and computed tomographic scanning could not pinpoint the location of the tumor. Thallium-201 and technetium-99m subtraction scintigraphy was also inconclusive in the precise localization of the tumor, but it did define the location retrospectively. However, magnetic resonance imaging (MRI) clearly demonstrated the parathyroid tumor as a high signal on T2-weighted image in the left upper part of the superior mediastinum. The intrathymic parathyroid oxyphil adenoma was resected. Therefore, MRI was considered an effective tool for the localization of parathyroid adenoma, particularly mediastinal parathyroid adenoma.
\end{abstract}

Key words: Primary hyperparathyroidism, Preoperative localization, Cystic parathyroid adenoma, Parathyroid oxyphil adenoma

The necessity of preoperative localization of parathyroid tumor in initially operative cases is a controversial issue (1-3). Magnetic Resonance Imaging (MRI) has been reported to be useful for preoperative localization of parathyroid tumors in patients with mediastinal parathyroid tumor (4) and in recurrent cases (5). The usefulness of MRI for preoperative localization of parathyroid adenoma (in the upper part of the superior mediastinum) is reported in this paper.

\section{REPORT OF A CASE}

A 59-year-old female was admitted to the Kumamoto National Hospital in October 1988 as a result of a complete medical examination of hypercalcemia. Three years previously, at another hospital, proteinuria was identified for the first time. In September 1988, she visited Kumamoto National
Hospital with complaints of a cold and swelling of the lower extremities. During the examination, proteinuria was confirmed and hypercalcemia was incidentally discovered. There was no history of lethargy, fatigue, polyuria, nausea, vomiting, fracture or kidney stones.

The patient's temperature was $36.5^{\circ} \mathrm{C}$, pulse 78 , and blood pressure $124 / 62 \mathrm{mmHg}$. On examination, the patient was an obese woman who appeared well and alert. The elastic diffuse goiter was palpated but neither the cervical lymph node nor mass was palpated. The heart was not enlarged. A grade $3+$ systolic ejection murmur was present and S4 sound was heard. The lungs were clear and the abdomen was normal. There was pretibial pitting edema. The tendon reflexes were slightly hyperactive throughout.

Laboratory data on admission were as follows: urinalysis showed a $2+$ test for protein, with several

From the Departments of Internal Medicine, *Surgery and **Pathology, Kumamoto National Hospital, Kumamoto Received for publication April 20, 1990; Accepted for publication September 13, 1990

Reprint requests should be addressed to Tatsuya Shimada, MD, Department of Internal Medicine,

Kumamoto National Hospital, 1-5 Ninomaru, Kumamoto 860, Japan 
hyaline casts per high-power field in the sediment. Serum albumin was slightly decreased $(3.3 \mathrm{~g} / \mathrm{dl})$ and fasting blood glucose was slightly increased (122 $\mathrm{mg} / \mathrm{dl})$. The serum calcium ranged from 11.1 to 12.3 $\mathrm{mg}$ per $100 \mathrm{ml}$; serum phosphorus ranged from 1.7 to $4.1 \mathrm{mg}$ per $100 \mathrm{ml}$. Twenty-four $\mathrm{h}$ urinary calcium and phosphorus ranged from 200 to $317 \mathrm{mg}$ and from 500 to $736 \mathrm{mg}$, respectively. Both thyroid microsomal and thyroglobulin antibodies gave a titer of $1: 1,600$. The creatinine clearance was $57.7 \mathrm{ml} /$ min. The concentration of serum immunoreactive parathyroid hormone (PTH-C) ranged from 0.80 to $0.92 \mathrm{ng}$ per $\mathrm{ml}$ (normal range: $0.2-1.00$ ), and was not suppressed not withstanding elevated levels of serum calcium. The nephrogeneous cyclic AMP was $5.0 \mathrm{nmol}$ per $100 \mathrm{ml} \cdot$ GF (normal range: $0.34-2.7$ ) and the tubular reabsorption of phosphate was $74.2 \%$. The concentration of $1,25(\mathrm{OH})_{2}$ vitamin $\mathrm{D}$ was $20 \mathrm{pg}$ per $\mathrm{ml}$ (normal range: $20-76$ ). The serum concentrations of corticotropin, thyroidstimulating hormone, growth hormone, prolactin, calcitonin, thyroid hormones, catecholamines, and thyroglobulin were within normal limits. The radiographs of the hands and skull did not reveal demineralization or ostitis fibrosa cystica. The abdominal radiograph and sonograph revealed no calcification of the kidneys. An electrocardiogram showed a normal QT interval.

The longitudinal sonogram demonstrated a hypoechoic mass adjacent to the left lobe of the thyroid gland $(1.2 \times 1.0 \mathrm{~cm})$. [The success of sonography depends greatly on the skill of the physician, especially in directing the probe to the mediastinum.] Although computed tomographic (CT) scanning, including contrast enhanced CT scanning, retrospectively demonstrated the parathyroid tumor, it was not prospectively demonstrated due to the indiscrimination between the parathyroid tumor and blood vessels.

The magnetic resonance transverse image, superior mediastinal section, demonstrated the soft tissue mass displaying the same signal as that of the thyroid gland on T1-weighted images (Fig. 1a) and a slightly higher signal than that of the thyroid gland on T2-weighted images (Fig. 1b). The T2-weighted image confirmed the low signal inside the soft tissue mass. Sagittal T1-weighted image clearly demonstrated the soft tissue mass adjacent to the left lower pole of the thyroid gland (Fig. 2a). Coronal T1-weighted image also clearly demonstrated the soft tissue mass surrounded by the left lobe of the thyroid gland, the trachea and the left carotid artery (Fig. 2b).

The thallium-201 and technetium-99m subtrac-

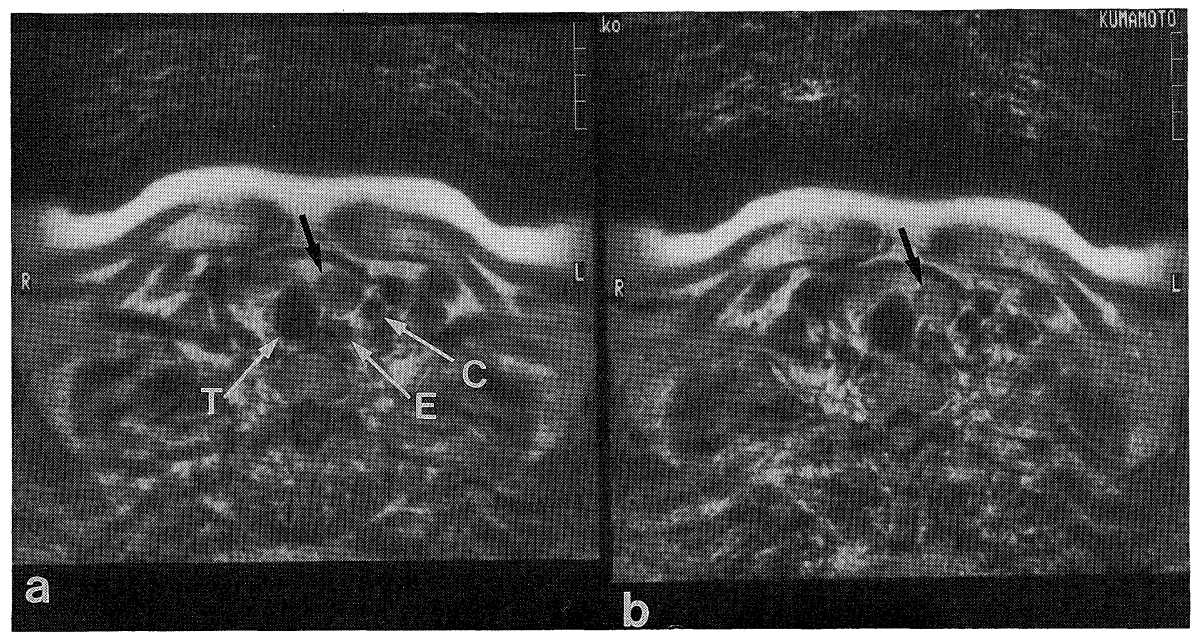

Fig. 1. Magnetic resonance transverse views of the superior mediastinum showing parathyroid adenoma (arrows). a) T1-weighted image (repetition time [TR] $=550 \mathrm{~ms}$, echo time [TE] $=30 \mathrm{~ms}$ ). A soft tissue mass (arrow) surrounded by trachea (T), esophagus (E) and carotid artery (C) is apparent. b) $\mathrm{T} 2$-weighted image ( $\mathrm{TR}=1,800 \mathrm{~ms}, \mathrm{TE}=50 \mathrm{~ms}$ ). The soft tissue mass (arrow) with low signal inside demonstrated a higher signal than that on the T1-weighted image. 




Fig. 2. Magnetic resonance $\mathrm{T} 1$-weighted images ( $\mathrm{TR}=400-450 \mathrm{~ms}, \mathrm{TE}=30 \mathrm{~ms}$ ) showing parathyroid adenoma (arrows). a) Coronal view confirms a soft tissue mass (arrow) surrounded by trachea (T), carotid artery (C) and the left lobe of thyroid gland (TG). b) Sagittal view confirms a soft tissue mass (arrow) adjacent to the left lower pole of thyroid gland (TG).

tion (T1-201/Tc-99m) scintigram demonstrated the specific uptake of thallium-201, corresponding to the left lower pole of the thyroid gland. The scintigram, however, hardly demonstrated the other organs surrounding the uptake. Therefore, it was impossible to study the anatomical relationship between the uptake and the surrounding organs.

Primary hyperparathyroidism was diagnosed based on the presence of a parathyroid tumor in the left upper part of superior mediastinum. Then, a parathyroid adenomectomy was performed. The tumor $(2.0 \times 1.4 \times 0.7 \mathrm{~cm}$, embedded in the thymic



Fig. 3. Large histologic section of the parathyroid adenoma, oxyphil cell type, with a lymphoid cyst in its central part. adipose tissue just behind the left clavicle) was removed. The brown colored tumor had a lymphoid cyst inside (Fig. 3). Preoperatively a low signal inside the soft tissue was demonstrated on the T2-weighted image. Postoperative pathological examination confirmed the cystic lesion identified by MRI. Pathologically, the greater part of the tumor (which was removed) consisted of diffusely proliferating oxyphil cells which contained large eosinophilic cytoplasm. A rim of chief cells outside the thin capsule was observed.

Before the operation was performed, the serum concentration of PTH-C was in the upper normal range. Four hours postoperatively, serum levels of calcium and phosphorus were normalized. Nine days after the parathyroid adenomectomy, the serum concentration of PTH-C decreased to lower normal limits. With regard to the renal disease, a diagnosis of chronic glomerulonephritis was clinically made and dilazep dihydrochloride was administered at a dose of $300 \mathrm{mg}$ per day. About two months after the start of administration, there was improvement in pretibial edema, proteinuria and urine sediment.

\section{DISCUSSION}

The methods of the localization of abnormal parathyroid tissue include both noninvasive and 
invasive procedures. The former includes esophagography, sonography, CT scanning, MRI and T1-201/Tc-99m scintigraphy. The latter includes angiography, differential venous catheterization with measurement of PTH serum samples, as well as needle aspiration of tumors (6). Stark et al (7) selected noninvasive procedures for the preoperative localization of abnormal parathyroid tissue. However, Satava et al (8) reported that abnormal parathyroid tissue causing primary hyperparathyroidism could be successfully resected in more than $90 \%$ of the cases without preoperative localization. Other researchers $(2,9)$ emphasized that the preoperative localization was necessary for the unsuccessful or recurrent cases, but not in the initially operated cases. However, we think that preoperative localization is necessary, even if the patient has initially had an operation. This proposal is based upon the following rationale. First, surgeons, who are not necessarily specialized in neck surgery must operate on patients with primary hyperparathyroidism, because the incidence of primary hyperparathyroidism has been increasing, as revealed by a prevalence rate of as high as 1 to 1,000 clinic patients (10). Therefore, preoperative localization is needed in order to successfully operate. Second, preoperative localization reduces the operating time and diminishes the incidence of complications (11). Third, it is known that abnormal parathyroid tissue is frequently accompanied by thyroid tumors (12). It is necessary to confirm the existence of thyroid tumors before exploration, since reoperation in the neck increases the incidence of complications and brings high risks. Fourth, preoperative localization is inevitable for mediastinal parathyroid tumors, which are observed in 10 to $20 \%$ of parathyroid tumors $(13,14)$.

The reported success rates for preoperative localization of parathyroid tumors have ranged from 59 to $80 \%$ using sonography $(4,7,15-17)$, from 74 to $80 \%$ using CT scanning $(4,7,15)$, from 75 to $100 \%$ using T1-201/Tc-99m scintigraphy $(4,5,7,11,15-17)$, and finally, from 69 to $90 \%$ using MRI (4, 5, 15, 18-20). However the success rate has been reported to reach more than $90 \%$ when using both sonography and T1-201/Tc-99m scintigraphy (7).

Since in the present case the parathyroid adenoma was situated in the upper part of superior mediastinum, it was difficult to demonstrate it by sonography. Therefore, as previously reported (4, 21 ), the sonography was thought to be inadequate to demonstrate mediastinal parathyroid tumors. In the case reported herein, preoperative localization could not be made prospectively by CT scanning because it was impossible to distinguish the parathyroid adenoma from the cervical blood vessels, even though contrasted with enhanced CT scanning. On the contrary, with MRI they were clearly distinguishable. Moreover, the T2-weighted image very clearly demonstrated the parathyroid adenoma as a higher signal than the T1-weighted image. In the present case, the T2-weighted image might have failed to demonstrate a parathyroid adenoma signal as high as previously reported (22), because the parathyroid adenoma had a cystic lesion in its central part. However, T2-weighted image has been reported to demonstrate not only parathyroid adenoma, but also thyroid tumor as a high signal (23). Since thyroid tumors are frequently known to be accompanied by abnormal parathyroid tissue (12), it is important and necessary to differentiate the parathyroid tumors from thyroid tumors. Moreover, adequate methods for distinguishing parathyroid from thyroid tumors have not been reported. Although Kier et al (19) reported that the T1-weighted image could help distinguish some cases of thyroid disease, which display high signals on both T1- and T2-weighted images. Further investigations are necessary on this point.

The MRI clearly made the anatomical localization of parathyroid adenoma, since it demonstrated the images on three planes: transverse, sagittal, and coronal views. Therefore, MRI was superior to sonography, CT scanning and scintigraphy in respect to the ability to demonstrate the anatomical relationship between the parathyroid adenoma and the surrounding organs. In addition, MRI makes it easier for surgeons to extract the superior mediastinal parathyroid tumor without complications.

In conclusion, MRI was considered useful for preoperative localization in patients with a parathyroid tumor, particularly a mediastinal parathyroid tumor. 


\section{REFERENCES}

1) Fine EJ. Parathyroid imaging: Its current status and future role. Semin Nucl Med 17: 350, 1987.

2) Winzelberg GG. Parathyroid imaging. Ann Intern Med 107: 64, 1987.

3) Roses DF, Sudarsky LA, Sanger J, Raghavendra BN, Reede DL, Blum M. The use of preoperative localization of adenomas of the parathyroid glands by thalliumtechnetium subtraction scintigraphy, high-resolution ultrasonography and computed tomography. Surg Gynecol Obstet 168: 99, 1989.

4) Levin KE, Clark OH. Localization of parathyroid glands. Annu Rev Med 39: 29, 1988.

5) Peck WW, Higgins CB, Fisher MR, Ling M, Okerlund $\mathrm{MD}$, Clark OH. Hyperparathyroidism: Comparison of MR imaging with radionuclide scanning. Radiology 163: 415, 1987.

6) McGarity WC, McKeown PP, Sewell CW. The role of routine biopsy of all parathyroid glands in primary hyperparathyroidism. Am Surg 51: 8, 1985.

7) Stark DD, Gooding GAW, Clark $\mathrm{OH}$. Noninvasive parathyroid imaging. Seminars US CT MR 6: 310, 1985.

8) Satava RM Jr, Beahrs OH, Scholz DA. Success rate of cervical exploration for hyperparathyroidism. Arch Surg 110: 625, 1975.

9) McHenry C, Walsh M, Jarosz H, et al. Resection of parathyroid tumor in the aorticopulmonary window without prior neck exploration. Surgery 104: 1090, 1988.

10) Boonstra CE, Jackson CE. Serum calcium survey for hyperparathyroidism: Results in 50,000 clinic patients. Am J Clin Pathol 55: 523, 1971.

11) Maslack MM, Brosbe RJ. Dual isotope parathyroid imaging. Clin Nucl Med 11: 622, 1986.

12) Hajjar ET, Salti IS. The co-existence of parathyroid and thyroid disease. 1. Primary hyperparathyroidism and thyroid carcinoma. Lebanese Med J 26: 241, 1973.
13) Roslyn JJ, Gordon HE, Mulder DG. Mediastinal parathyroid adenomas. A cause of persistent hyperparathyroidism. Am Surg 49: 523, 1983.

14) Nathaniels EK, Nathaniels AM, Wang CA. Mediastinal parathyroid tumors: A clinical and pathological study of 84 cases. Ann Surg 171: 165, 1970.

15) Kneeland JB, Krubsack AJ, Lawson TL, et al. Enlarged parathyroid glands: High-resolution local coil MR imaging. Radiology 162: 143, 1987.

16) Winzelberg GG, Hydovitz JD, O'Hara KR, et al. Parathyroid adenomas evaluated by T1-201/Tc-99m pertechnetate subtraction scintigraphy and highresolution ultrasonography. Radiology 155: 231, 1985.

17) Gooding GAW, Okerlund MD, Stark DD, Clark OH. Parathyroid imaging: Comparison of double-tracer (T1-201, Tc-99m) scintigraphy and high-resolution US. Radiology 161: 57, 1986.

18) Spritzer CE, Gefter WB, Hamilton R, Greenberg BM, Axel L, Kressel HY. Abnormal parathyroid glands: High-resolution MR imaging. Radiology 162: 487, 1987.

19) Kier R, Blinder RA, Herfkens RJ, Leight GS, Spritzer CE, Carroll BA. MR imaging with surface coils in primary hyperparathyroidism. J Comput Assist Tomogr 11: 863, 1987.

20) Hamilton R, Greenberg BM, Gefter W, Kressel H, Spritzer C. Successful localization of parathyroid adenoma by magnetic resonance imaging. Am J Surg 155: 370, 1988.

21) Reading CC, Charboneau JW, James EM, et al. Postoperative parathyroid high-frequency sonography: Evaluation of persistent or recurrent hyperparathyroidism. AJR 144: 399, 1985.

22) Kier R, Herfkens RJ, Blinder RA, Leight GS, Utz JA, Silverman PM. MRI with surface coil for parathyroid tumors: Preliminary investigation. AJR 147: 497, 1986.

23) Stark DD, Moss AA, Gamsu G, Clark OH, Gooding GAW, Webb WR. Magnetic resonance imaging of the neck. II. Pathologic findings. Radiology 150: 455, 1984. 